\title{
Bypass Flow Study
}

\author{
Richard R. Schultz
}

September 2011

The INL is a

U.S. Department of Energy

National Laboratory

operated by

Battelle Energy Alliance

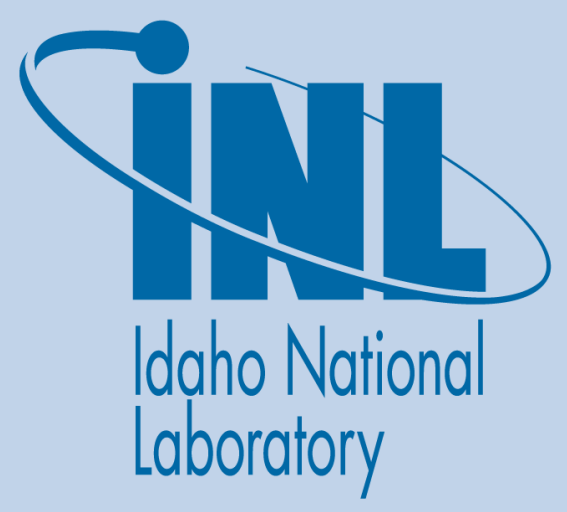

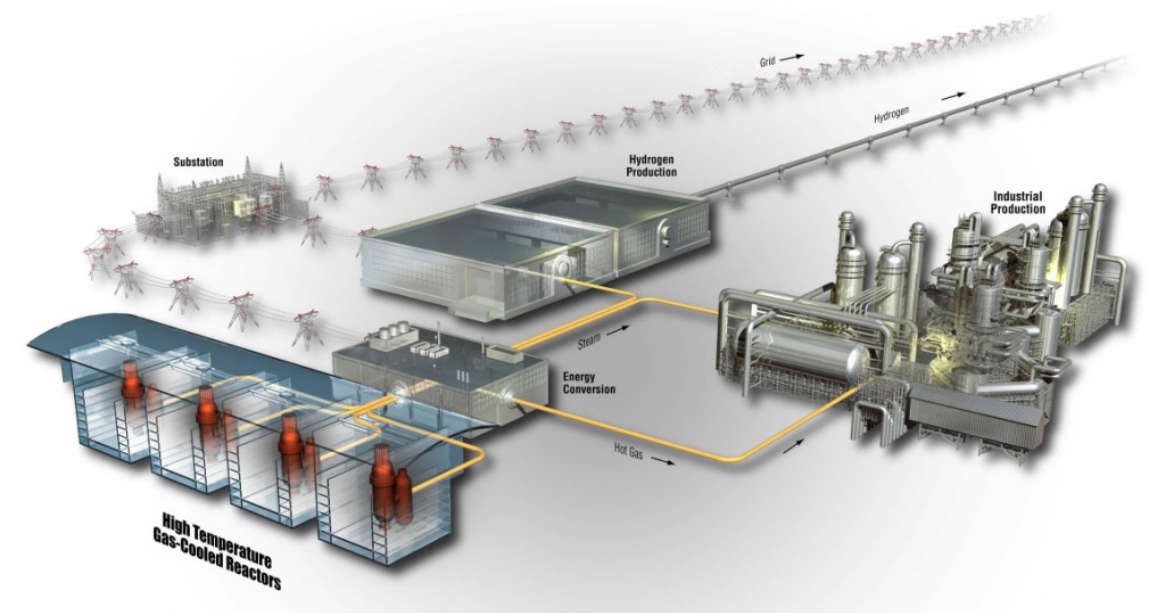




\section{DISCLAIMER}

This information was prepared as an account of work sponsored by an agency of the U.S. Government. Neither the U.S. Government nor any agency thereof, nor any of their employees, makes any warranty, expressed or implied, or assumes any legal liability or responsibility for the accuracy, completeness, or usefulness, of any information, apparatus, product, or process disclosed, or represents that its use would not infringe privately owned rights. References herein to any specific commercial product, process, or service by trade name, trade mark, manufacturer, or otherwise, does not necessarily constitute or imply its endorsement, recommendation, or favoring by the U.S. Government or any agency thereof. The views and opinions of authors expressed herein do not necessarily state or reflect those of the U.S. Government or any agency thereof. 


\title{
Bypass Flow Study
}

\author{
Richard R. Schultz
}

September 2011

\section{Idaho National Laboratory Next Generation Nuclear Plant Project Idaho Falls, Idaho 83415}

\author{
http://www.inl.gov
}

\section{Prepared for the}

U.S. Department of Energy

Office of Nuclear Energy

Under DOE Idaho Operations Office

Contract DE-AC07-05ID14517 



\section{Next Generation Nuclear Plant Project}

\section{Bypass Flow Study}

INL/EXT--11-23311

September 2011

Approved by:
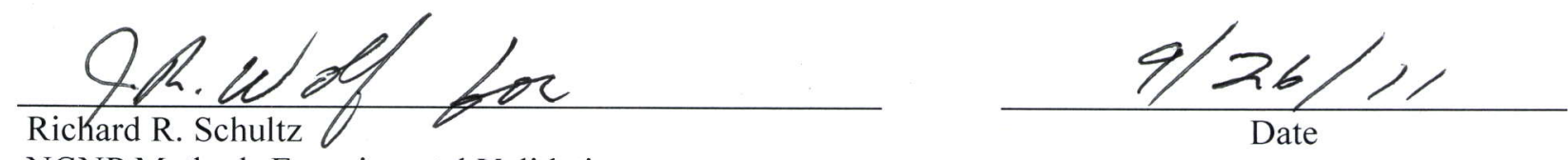

NGNP Methods Experimental Validation
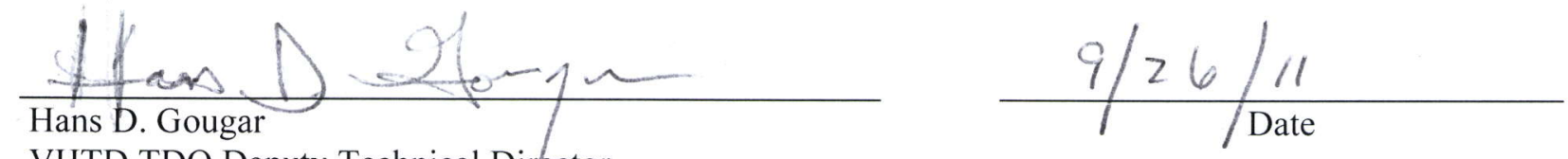

VHTD TDO Deputy Technical Director 



\begin{abstract}
Fluid dynamics experiments are being conducted in the matched-index-ofrefraction flow system at the Idaho National Laboratory to develop benchmark databases. The data will be used to assess computational fluid dynamics solutions of the momentum equations, scalar mixing, and turbulence models for the flow ratios between coolant channels and bypass gaps in the interstitial regions of typical prismatic standard fuel element or upper reflector block geometries of typical modular high-temperature gas-cooled reactors in the limiting case of negligible buoyancy and constant fluid properties. The experiments use particle image velocimetry to measure the velocity fields that will populate the bypass flow study database. The matched-index-of-refraction modular high-temperature gas-cooled reactor bypass flow experiment measures flow velocity fields in the coolant channels and interstitial gaps between typical prismatic block standard fuel elements (SFEs) or upper reflector blocks.
\end{abstract}




\section{CONTENTS}

ABSTRACT.

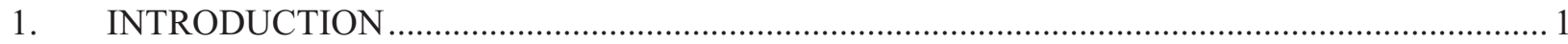

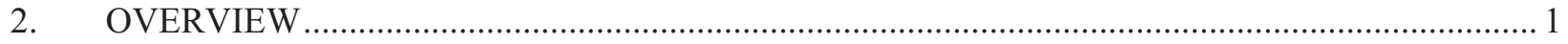

2.1 MIR Bypass Flow Experiment Measurement Technique …................................................ 3

2.2 MIR Bypass Flow Experiment Measurement Locations …................................................. 4

2.3 Uncertainties in the MIR Bypass Flow Experiment......................................................... 5

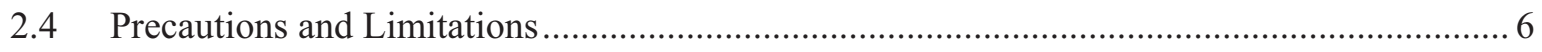

3. SCALING AND MEASUREMENT AND TEST AND EQUIPMENT ..................................... 6

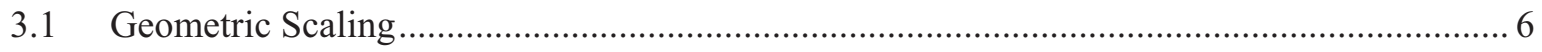

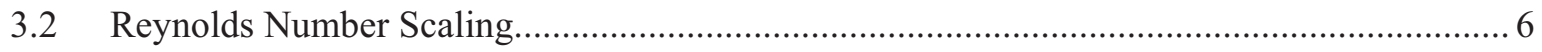

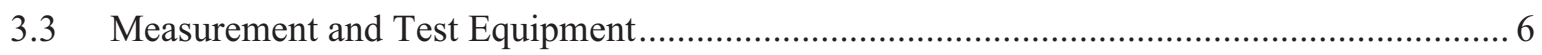

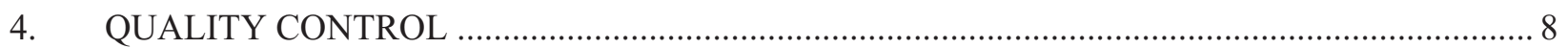

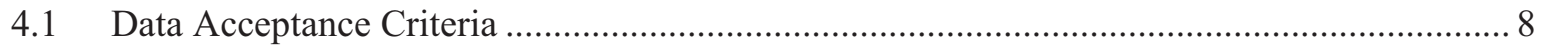

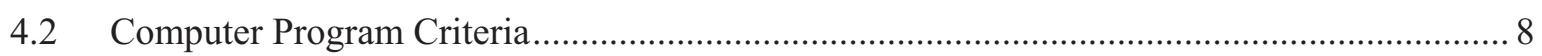

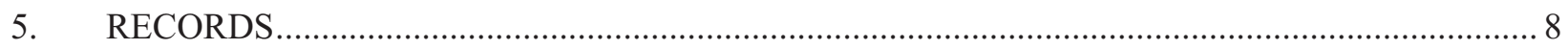

6. PIV AND PRESSURE MEASUREMENT COLLECTION PLAN ............................................... 8

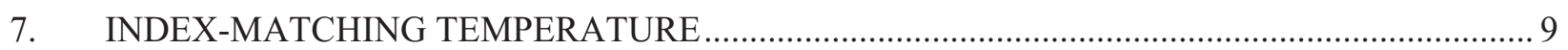

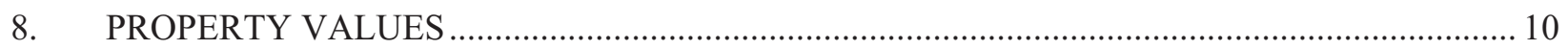

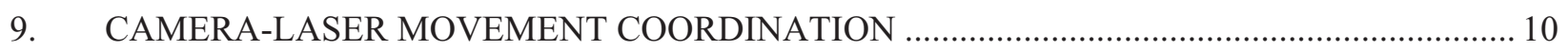

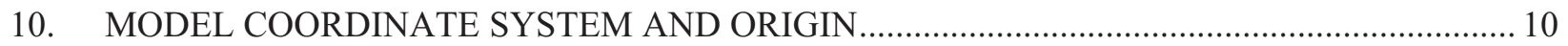

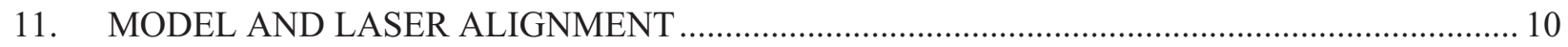

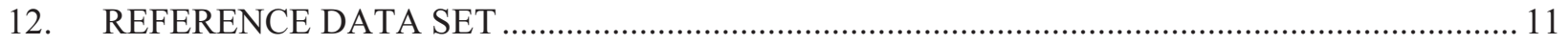

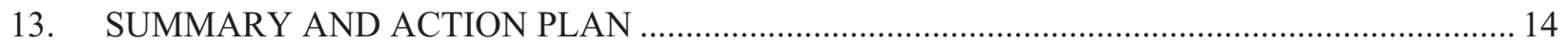

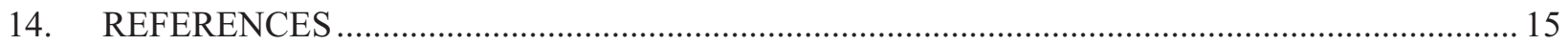

\section{FIGURES}

Figure 1. Relationship between three prismatic blocks to the "Y" gap geometry of their vertex................ 1

Figure 2. Blow-up of MIR bypass flow experiment. Plan view. ............................................................ 2

Figure 3. Exploded illustration of the INL MIR bypass flow experiment model assembly....................... 3

Figure 4. Complete assembly of the INL MIR bypass flow experiment. ................................................ 3 


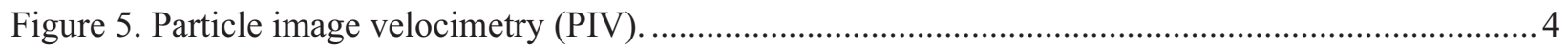

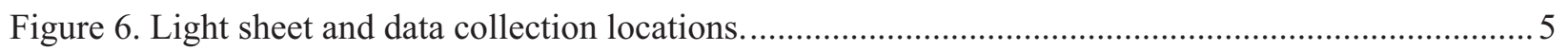

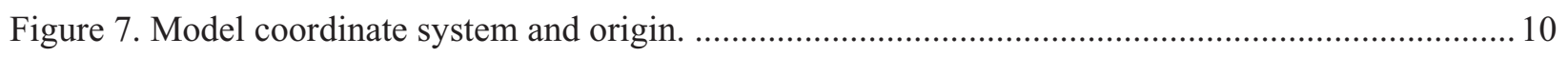

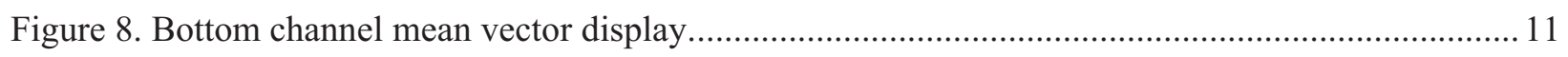

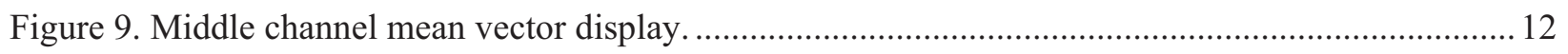

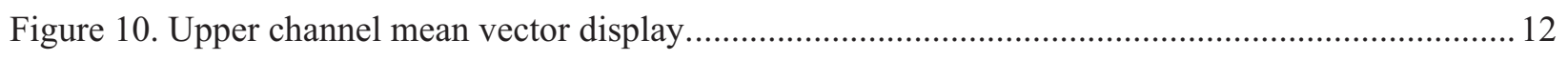

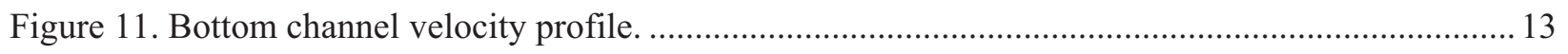

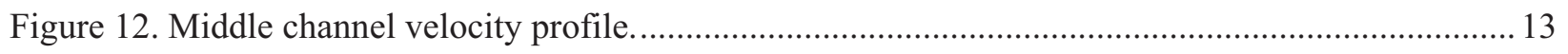

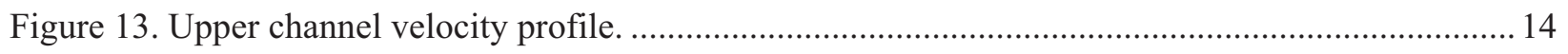

\section{TABLES}

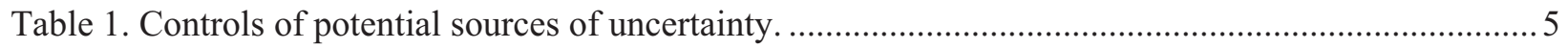

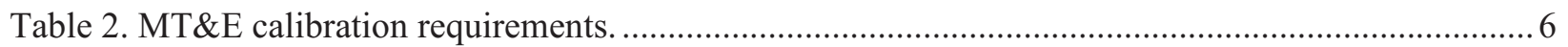

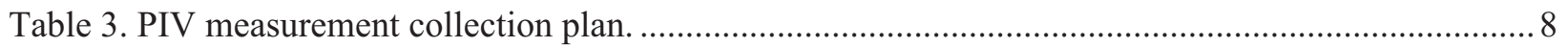




\section{Bypass Flow Study}

\section{INTRODUCTION}

Fluid dynamics experiments are being conducted in the matched-index-of-refraction (MIR) flow system at the Idaho National Laboratory (INL) to develop benchmark databases. The data will be used to assess computational fluid dynamics solutions of the momentum equations, scalar mixing, and turbulence models for the flow ratios between coolant channels and bypass gaps in the interstitial regions of typical prismatic standard fuel element (SFE) or upper reflector block geometries of typical modular hightemperature gas-cooled reactors (MHTGR) in the limiting case of negligible buoyancy and constant fluid properties. The experiments use particle image velocimetry (PIV) to measure the velocity fields that will populate the bypass flow study database.

\section{OVERVIEW}

The MIR MHTGR bypass flow experiment measures flow velocity fields in the coolant channels and interstitial gaps between typical prismatic block standard fuel elements (SFEs) or upper reflector blocks.

The configuration of the MIR bypass flow experiment is scaled to match the bypass geometry for the prismatic core of the MHTGR. Figure 1 shows the relationship of three adjacent prismatic blocks for the MHTGR in a plan view. The interstitial gaps have a maximum width of approximately $3.9 \mathrm{~mm}$ prior to irradiation. ${ }^{1}$ The gaps between each prismatic block come together at vertices that occur at the corner of three adjacent prismatic blocks (see Figure 1) and form a "Y." The gaps themselves are characterized not only by the gap size (the flow area per unit length), but also by the frictional pressure drop inherent to the graphite gap walls. In contrast, the vertex passage has a vanishingly small wall influence as the limit. Consequently, it is thought that the bypass flow will tend to bias itself to the vertices. Therefore, the interactions between the flow in the gaps and the vertex are being studied in the MIR bypass flow experiment.

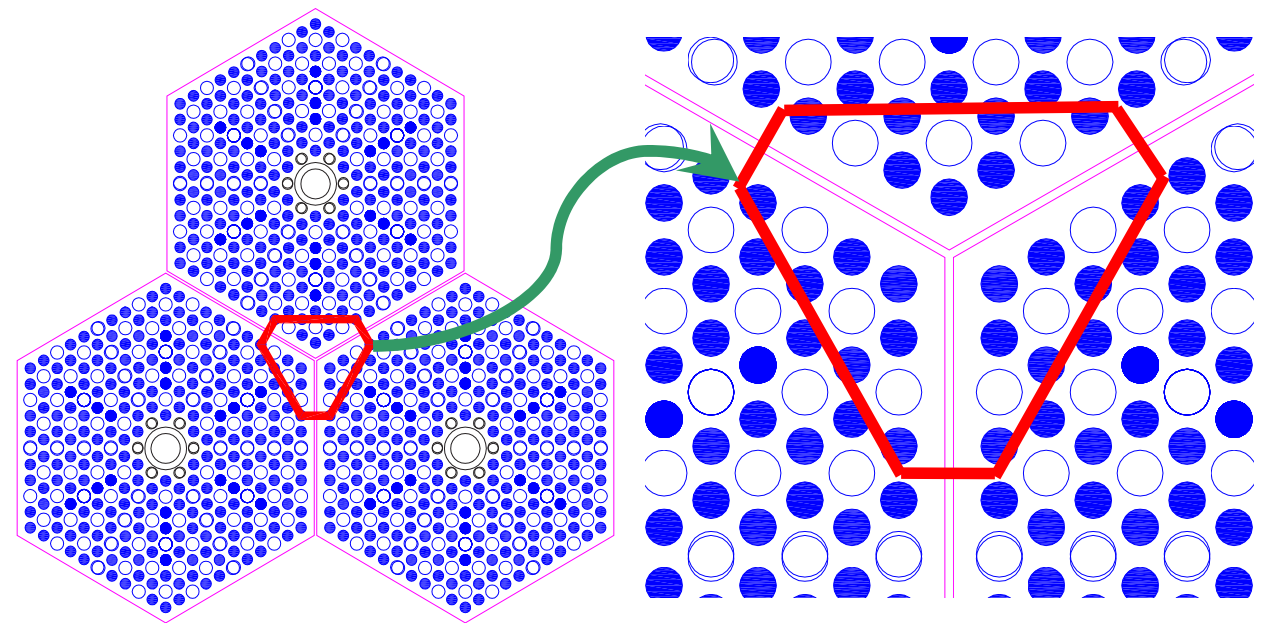

Figure 1. Relationship between three prismatic blocks to the "Y" gap geometry of their vertex.

As described in Schultz 2009, ${ }^{2}$ the MIR bypass flow experiment is designed to study the behavior of flow in the interstitial gap region, in particular, to quantify the flow in the gap in relation to the flow in the vertex and the coolant channel regions of SFEs. Because the MIR bypass flow study is an isothermal experiment performed at room temperature, the effects of density gradients, and thus the influence of 
temperature, is not being studied. Hence the MIR experiments focus on the flow regimes that are momentum dominated as opposed to density-gradient dominated flows.

The experimental concept is shown in the right-hand portion of Figure 1. Typically, the coolant channel Reynolds number, which is based on the channel hydraulic diameter of the MHTGR at full power, is on the order of 60,000 and in excess of 3,500 at low power $(\sim 10 \%$ power). Design analyses of the planned MIR experiment indicate that a coolant channel Reynolds number of about 5,700 can be achieved with the model scaled to 2.016 times the actual size of a SFE to enhance data resolution.

Figure 2 shows a more detailed plan view drawing of the configuration shown in the right-hand side of Figure 1 with the symmetric region of three prismatic blocks that were selected for the MIR bypass flow experiment. It is important to note that the selected area includes the three coolant channels closest to the vertex of the prismatic SFE and only includes the area of the prismatic SFE that could reasonably be expected to influence flow through the coolant channels and interstitial gaps in this area. Also, the region selected includes the intersection of three prismatic SFEs so that the flow in the area where the three interstitial gaps meet (the vertex) can be studied.

The experimental hardware design shown in Figure 2 includes all three SFE sections that form the interstitial gaps, the gap vertex, and coolant channels. The individual SFE sections are fabricated from fused quartz tubes and solid end caps with holes machined into the end caps. The bypass flow gap widths can be adjusted to approximately 2,6 , and $10 \mathrm{~mm}(1,3$, and $5 \mathrm{~mm}$ widths in the actual reactor). The quartz end caps will be chamfered at the inlet, as shown in Figure 2, to match the design of the MHGTR prismatic SFE structure.

Figure 3 is an exploded illustration of the model assembly. The assembly includes an aluminum hemispherical dome (red) that models the upper plenum of a typical MHTGR, a quartz inlet plenum (green) that models the region above the upper reflector surface, a quartz model of the coolant channels and interstitial gaps in an SFE (purple and pink), and a model of a second SFE to model the radial gap between the stack of vertical SFEs.

Figure 4 shows the complete assembly. The locations of specific measurement planes were determined by coordination with the computational fluid dynamics simulation team (see Figure 6.). 


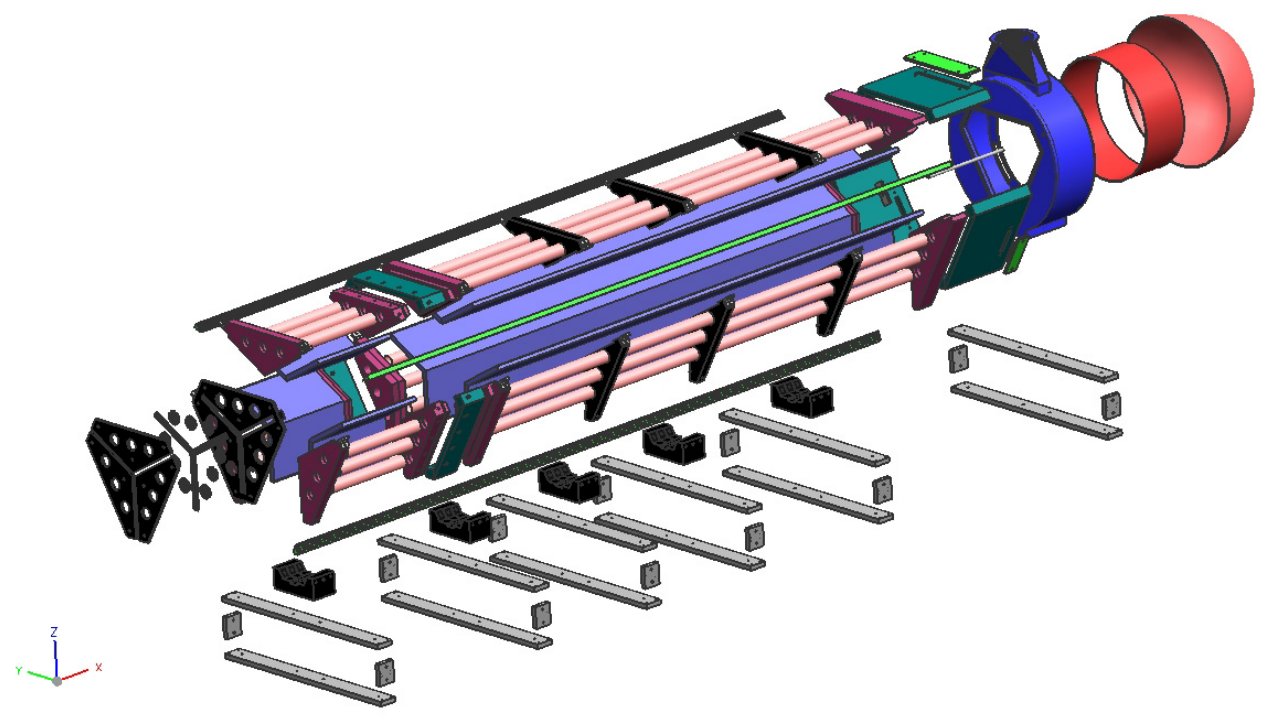

Figure 3. Exploded illustration of the INL MIR bypass flow experiment model assembly.

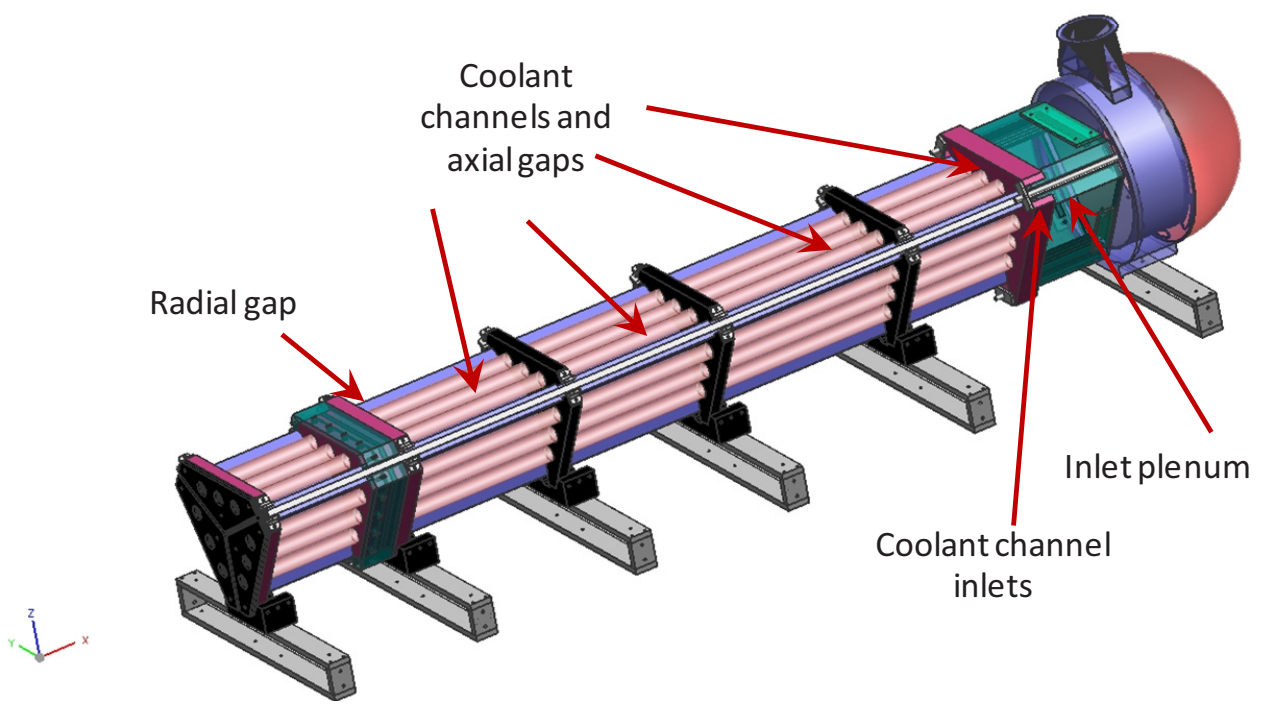

Figure 4. Complete assembly of the INL MIR bypass flow experiment.

\subsection{MIR Bypass Flow Experiment Measurement Technique}

The INL MIR Flow Facility stereo PIV system was used to generate data for this reference data set. As shown in Figure 5, the flow is seeded with approximately neutrally buoyant particles, or at least particles that can be analytically shown to closely follow the fluid streamlines. When a laser pulse illuminates the seed particles, the illuminated seed particles are captured as bright spots on the digital camera image chip. When a subsequent laser pulse is generated (double-pulsed laser), a second digital image of the illuminated seed particles is recorded. Then a comparison between the locations of the illuminated particles on the two images based on illumination intensity of the seed particles is performed. The PIV software moves the two images relative to one another to match up the seed particle intensities in the two images. The distance moved to match up the two images $(\Delta \mathrm{x})$ establishes the distance traveled by specific particles in the pre-set time interval $(\Delta \mathrm{t})$. The ratio of these quantities $(\Delta \mathrm{x} / \Delta \mathrm{t})$ is the velocity. The velocity is displayed with both magnitude and direction. 


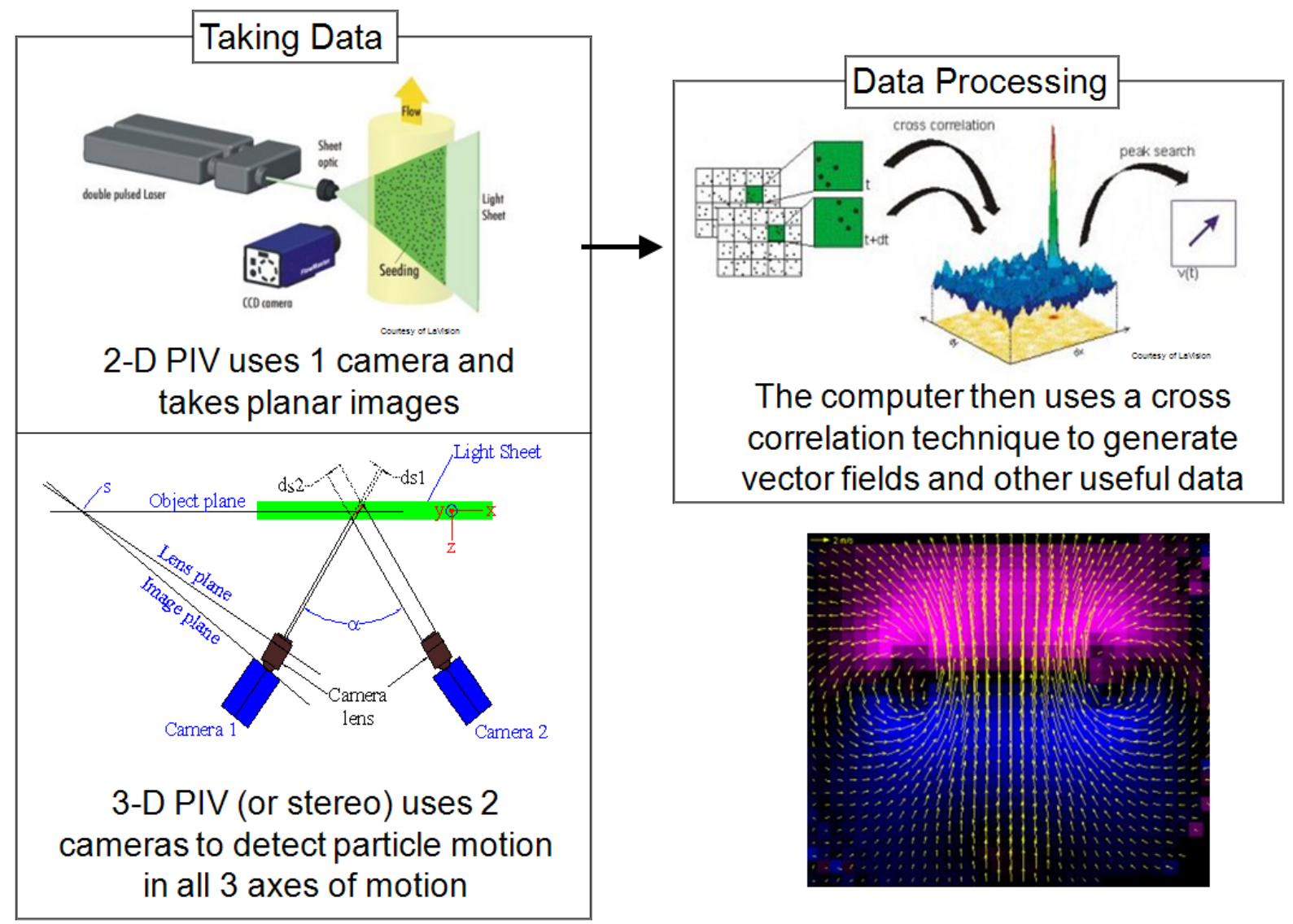

Figure 5. Particle image velocimetry (PIV).

Two-dimensional PIV is shown in the left-hand side of Figure 5. When two cameras are employed, stereo (or 3-D) data can be obtained. For the MIR bypass flow experiment, the laser light sheet is located beneath the test section and oriented parallel to the axial centerline of the bypass flow model. A crosscorrelation algorithm is employed to calculate the velocity vectors. Typical data generated by PIV, shown in the lower right hand corner of Figure 5, include a set of velocity vectors indicating both the magnitude (shown by the color or length of the vector) and the direction of the particles (direction of the vector) and thus the 3-D flow in the flow field.

\subsection{MIR Bypass Flow Experiment Measurement Locations}

Figure 6 displays the three locations of the double-pulsed laser that will be used to collect velocity field data. At each location, the laser light sheet will be moved across the model at $1 \mathrm{~mm}$ intervals to cover the entire width of the model (approximately 273 PIV files). This process will be repeated for each gap size (2, 5, and $10 \mathrm{~mm})$ and each coolant channel Reynolds number (low, medium, and high). 


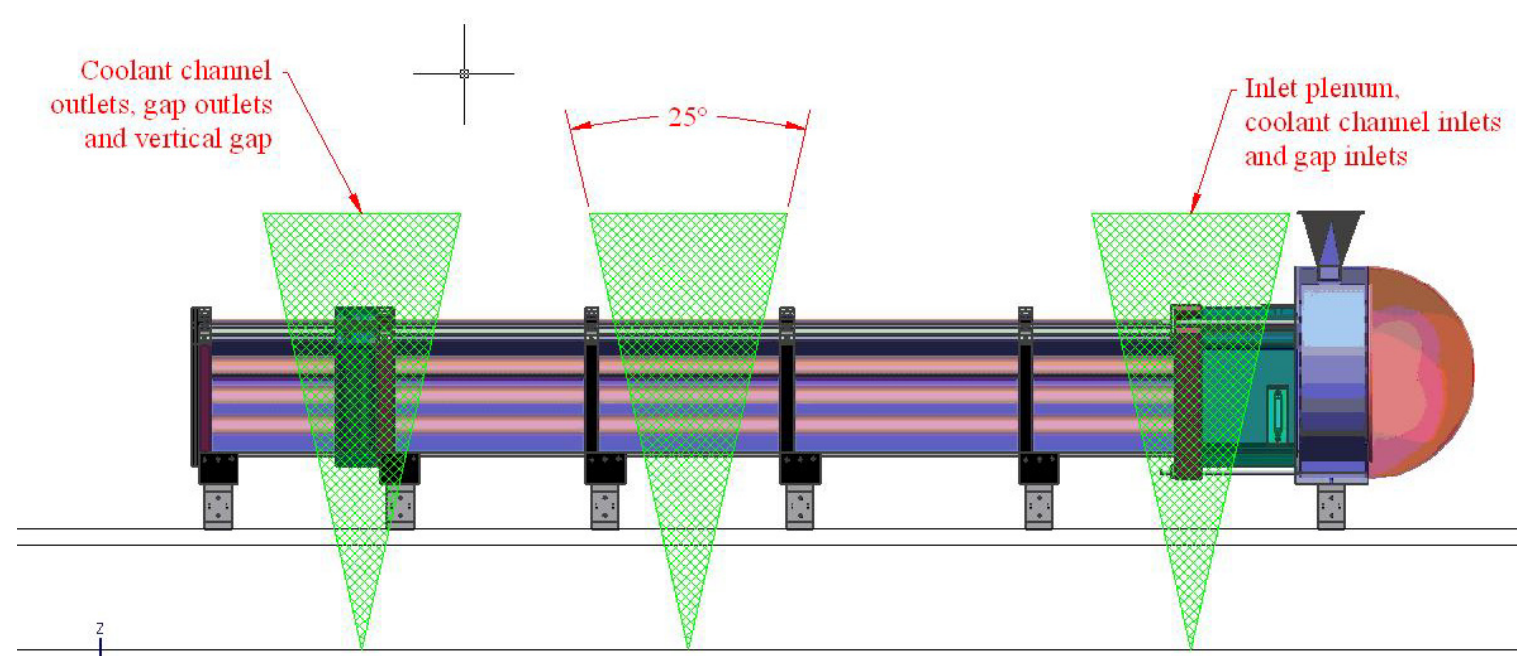

Figure 6. Light sheet and data collection locations.

\subsection{Uncertainties in the MIR Bypass Flow Experiment}

The methodology for evaluating the measurement uncertainties in the MIR bypass flow experiments was defined on the basis of the work to evaluate the measurement uncertainties for the MIR lower plenum mixing experiments. ${ }^{3}$ The components of velocity that must be evaluated individually to complete ${ }^{\mathrm{a}}$ an overall uncertainty in velocity measurements are scaling uncertainty, displacement or position uncertainty, and uncertainty in the time interval. To estimate the uncertainties in these components, the following categories of uncertainty are considered: (a) uncertainties in the PIV calibration algorithms, (b) uncertainties in image quality/flow visualization, (c) uncertainties in image detection, and (d) uncertainties in data processing. Uncertainties in the properties of the working fluid (mineral oil), calculated volume flow rates and Reynolds numbers, and particle tracking are also considered. The procedures and guidelines established by the International Towing Tank Conference ${ }^{4}$ are the principal procedures and guidelines used in the uncertainty analysis of the bypass flow velocity measurements. This analysis is complimented by some of the methods described by McEligot, McIlroy, and Johnson ${ }^{5}$ that apply to this specific situation. The uncertainty analysis for this study is in progress and will be included in the final report.

Table 1. Controls of potential sources of uncertainty.

\begin{tabular}{|lll|}
\hline \multicolumn{1}{|c|}{ Uncertainty Source } & \multicolumn{1}{c|}{ Control } & \multicolumn{1}{c|}{ Accuracy } \\
\hline Position measurement error & None (software dependent) & \pm 0.2 pixel $^{6}$ \\
Geometry & Design drawings and as-built measurements & $\pm 0.127 \mathrm{~mm}$ \\
Position (x, y, and z) of model, & Linear stages and digital readout, oil temperature & $\pm 5 \mu \mathrm{m}$ (traverse) \\
cameras, laser and light sheet & & $\pm 5 \mu \mathrm{m}$ (laser z) \\
Time & DaVis software & $<1 \mathrm{~ns}$ (negligible) \\
Index-of-Refraction & Temperature & $\pm 0.05^{\circ} \mathrm{C}$ \\
Oil density & Temperature & $\pm 0.05^{\circ} \mathrm{C}$ \\
Oil viscosity & Temperature & $\pm 0.05^{\circ} \mathrm{C}$ \\
Measured volume flow rate & Turbine flow meter & $\pm 0.25 \%$ \\
\hline
\end{tabular}

a Under some circumstances other uncertainties may become important, e.g., treatment of near-wall quantities as well as calibration and parallax uncertainties. However, to date, these uncertainties have not been either of interest or of a sufficient magnitude to consider. 
Fabrication drawings included dimension tolerances. The fabricated components of the model were measured in as-built dimensions, and these dimensions are being used in the uncertainty analysis. The design and as-built measurements are in the study files and are a part of the electronic lab notebook.

\subsection{Precautions and Limitations}

All precautions, limitations, hazards, hazard mitigation, and actions to be taken in the event of an accidental oil spill are contained in the MIR Lab work control documentation. ${ }^{\mathrm{b}}$

\section{SCALING AND MEASUREMENT AND TEST AND EQUIPMENT}

\subsection{Geometric Scaling}

The model was scaled geometrically to an SFE of the General Atomics SFE design ${ }^{7}$ and graphite block requirements for the GT-MHR reactor core. ${ }^{8,9}$ The geometry scale is based on the diameter of available quartz tubes (32 mm ID) and resulted in an overall geometric scale of 1:2.016 (actual: model).

\subsection{Reynolds Number Scaling}

Reynolds number scaling is based on the coolant channel diameter and mass flow rates of an MHGTR. An analysis of the total dynamic head in the bypass flow model and inlet plumbing indicated that the MIR flow facility auxiliary loop could produce a maximum volume flow rate of approximately $1,230 \mathrm{~L} / \mathrm{min}(325 \mathrm{gpm})$ through the model. This flow rate would produce a coolant channel Reynolds number of about 5,700, which is in the low power range of a gas-cooled reactor.

\subsection{Measurement and Test Equipment}

All measurement and test equipment (M\&TE) was selected based on requirements for type, range, accuracy, and tolerance.

Table 2. MT\&E calibration requirements.

\begin{tabular}{|c|c|c|}
\hline M\&TE & Nomenclature & Calibration Requirement \\
\hline Black Stack Module Set & Hart Scientific Model 1560 & $\begin{array}{l}\text { Calibrate before use, recalibrate in accordance } \\
\text { with the next cal due date established by the } \\
\text { Calibration Lab. }\end{array}$ \\
\hline CCD Cameras (2) & $\begin{array}{l}\text { LaVision PIV Imager Pro Plus } \\
2 \mathrm{M}\end{array}$ & NA - certified checklist from manufacturer \\
\hline Coriolis Flow Meter & Micro Motion & $\begin{array}{l}\text { Performance check - calibration not required } \\
\text { as per manufacturer }\end{array}$ \\
\hline Dial indicator & SPI 24-333-7 0.001-1.0 inch & $\begin{array}{l}\text { Calibrate before use, recalibrate in accordance } \\
\text { with the next cal due date established by the } \\
\text { Calibration Lab. }\end{array}$ \\
\hline Digital caliper & Fowler 12 inch digital caliper & $\begin{array}{l}\text { Calibrate before use, recalibrate in accordance } \\
\text { with the next cal due date established by the } \\
\text { Calibration Lab. }\end{array}$ \\
\hline
\end{tabular}

b Research and Development Laboratory Instruction Matched Index-of-Refraction Flow System 1350-07-IEDF. 


\begin{tabular}{|c|c|c|}
\hline M\&TE & Nomenclature & Calibration Requirement \\
\hline $\begin{array}{l}\text { Turbine flow meters } \\
\text { with digital readouts }\end{array}$ & $\begin{array}{l}\text { \#FT-48C800-LB(S) } \\
\text { Property ID 709485 } \\
\text { Ser\# 48127 } \\
\text { Readout Model } \\
\text { LN-5-A-V1BC } \\
\text { Property ID 728600 } \\
\text { Ser\# LKA10032180 } \\
\text { \#FT-48C1SW-LEA-1 } \\
\text { Property ID 709009 } \\
\text { Ser\# 480852 } \\
\text { Readout Model } \\
\text { LN-5-C-V1BC } \\
\text { Property ID 728338 } \\
\text { Ser\# LKA10032181 }\end{array}$ & $\begin{array}{l}\text { Calibrate before use, recalibrate in accordance } \\
\text { with the next cal due date established by the } \\
\text { Calibration Lab. }\end{array}$ \\
\hline $\begin{array}{l}\text { Glass scale linear } \\
\text { encoders }\end{array}$ & $\begin{array}{l}\text { Ser\# } 98106622 \text { - Camera x } \\
\text { Ser\# } 98114929 \text { - Camera z } \\
\text { Ser\# } 15599699 \text { - Laser z }\end{array}$ & $\begin{array}{l}\text { Calibrate in MIR Lab before use, recalibrate in } \\
\text { MIR Lab in accordance with the next cal due } \\
\text { date established by the Calibration Lab. }\end{array}$ \\
\hline Nd:YAG laser & PIV double-pulsed laser & NA - factory-set specifications \\
\hline PIV System & $\begin{array}{l}\text { LaVsion DaVis software } \\
\text { camera and PTU calibration }\end{array}$ & $\begin{array}{l}\text { This is NOT a "calibration" against a traceable } \\
\text { standard. The use of LaVision certified PIV } \\
\text { calibration plates establishes the spatial } \\
\text { calibration of camera images so that known } \\
\text { separation between points in the object plane } \\
\text { (in mm) are specified. The Self-calibration } \\
\text { procedure corrects for misalignments between } \\
\text { the calibration plate and laser light sheet. }\end{array}$ \\
\hline Pressure transducers & $\begin{array}{l}\text { PP - Model inlet plenum } \\
\text { P1-2 - Model SFE 1-2 gap } \\
\text { PI - Auxiliary loop outlet } \\
\text { PO - Model outlet }\end{array}$ & $\begin{array}{l}\text { Calibrate before use, recalibrate in accordance } \\
\text { with the next cal due date established by the } \\
\text { Calibration Lab. }\end{array}$ \\
\hline PRT Probe & $\begin{array}{l}\text { Hart Scientific Model } 5610 \\
\# 1193-1685 \text { \& \#1193-1681 }\end{array}$ & $\begin{array}{l}\text { Calibrate before use, recalibrate in accordance } \\
\text { with the next cal due date established by the } \\
\text { Calibration Lab. }\end{array}$ \\
\hline Seeding particles & SH400S20 Silvered Spheres & $\begin{array}{l}\text { NA - Certificate of Analysis from } \\
\text { manufacturer }\end{array}$ \\
\hline Temperature thermistors & $\begin{array}{l}\text { TAD - Test section inlet door- } \\
\text { side } \\
\text { TAO - Test section inlet } \\
\text { operator-side } \\
\text { TM - Model inlet plenum } \\
\text { TK - Model external } \\
\text { midstream } \\
\text { TN - Model outlet }\end{array}$ & $\begin{array}{l}\text { Calibrate before use with Black Stack Module } \\
\text { Set and recalibrate after use. }\end{array}$ \\
\hline
\end{tabular}




\section{QUALITY CONTROL}

\subsection{Data Acceptance Criteria}

PIV velocity measurements were required to be within reasonable agreement with the theoretical/qualitative calculations using disciplined engineering judgment and first principles.

\subsection{Computer Program Criteria}

All of the computer software used for this study (DaVias [PIV system], Tecplot 360, MathCad, AutoCad, MS Word and MS Excel) met QL3 software standards and were managed in accordance with the General Software Management Plan for the VHTR TDO PLN-2247, Revision 1. Hand calculations were conducted to confirm measured parameters.

\section{RECORDS}

A laboratory notebook, electronic experiment logs, electronic data files, design and fabrication drawings and as-built drawings are being maintained as quality assurance records and controlled in accordance with the Department Records Management Plan.

The MIR-INERI Core Bypass Flow Laboratory Notebook document number LAB-144 is being maintained in accordance with Laboratory Notebook Instructions and Best Management Practices in the Laboratory Notebook.

Computer software and hardware certifications and M\&TE calibrations are being maintained in MIR Lab files.

\section{PIV AND PRESSURE MEASUREMENT COLLECTION PLAN}

The PIV measurement collection plan is presented in Table 3.

Table 3. PIV measurement collection plan.

\begin{tabular}{|lccccc|}
\hline $\begin{array}{c}\text { Reynolds Number } \\
\text { (based on coolant } \\
\text { channel diameter) }\end{array}$ & $\begin{array}{c}\text { Axial Gap } \\
(\mathrm{mm})\end{array}$ & $\begin{array}{c}\text { Radial Gap } \\
(\mathrm{mm})\end{array}$ & $\begin{array}{c}\text { Inlet Planes } \\
(273 \text { files each) }\end{array}$ & $\begin{array}{c}\text { Mid-channel Plane } \\
(111 \text { files each) }\end{array}$ & $\begin{array}{c}\text { Outlet Plane } \\
(273 \text { files each) }\end{array}$ \\
\hline Medium & 6 & 6 & $-136<\mathrm{z}<+136$ & $-55<\mathrm{z}<+55$ & $-136<\mathrm{z}<+136$ \\
Low & 6 & 6 & $-136<\mathrm{z}<+136$ & $-55<\mathrm{z}<+55$ & $-136<\mathrm{z}<+136$ \\
High & 6 & 6 & $-136<\mathrm{z}<+136$ & $-55<\mathrm{z}<+55$ & $-136<\mathrm{z}<+136$ \\
Low & 2 & 2 & $-136<\mathrm{z}<+136$ & $-55<\mathrm{z}<+55$ & $-136<\mathrm{z}<+136$ \\
Medium & 2 & 2 & $-136<\mathrm{z}<+136$ & $-55<\mathrm{z}<+55$ & $-136<\mathrm{z}<+136$ \\
High & 2 & 2 & $-136<\mathrm{z}<+136$ & $-55<\mathrm{z}<+55$ & $-136<\mathrm{z}<+136$ \\
Low & 10 & 10 & $-136<\mathrm{z}<+136$ & $-55<\mathrm{z}<+55$ & $-136<\mathrm{z}<+136$ \\
Medium & 10 & 10 & $-136<\mathrm{z}<+136$ & $-55<\mathrm{z}<+55$ & $-136<\mathrm{z}<+136$ \\
High & 10 & 10 & $-136<\mathrm{z}<+136$ & $-55<\mathrm{z}<+55$ & $-136<\mathrm{z}<+136$ \\
\hline
\end{tabular}

Pressure measurements will be collected during all of the PIV measurements listed in Table 3.

Measurements will be collected at three locations in the upper plenum, at the top, and in the center of the gap between the upper and lower SFE block models. 


\section{INDEX-MATCHING TEMPERATURE}

The index-matching temperature was calculated for mineral oil and quartz at the light-emitting wavelength of the Nd: YAG laser $(532 \mathrm{~nm})$.

Budwig and Westin ${ }^{10}$ determined the index-of-refraction of Drakeol 5 (light mineral oil) as a function of temperature as

$$
n_{\text {Oil }}=1.46741-3.5909 \times 10^{-4} \cdot \mathrm{T} \quad(\mathrm{T} \text { in degrees })
$$

McCreery ${ }^{11}$ determined the index-of-refraction of mineral oil at $532 \mathrm{~nm}$ by assuming a constant, linear slope for $d n / d \lambda$ as a function of temperature as

$$
\begin{aligned}
& n_{\text {Oil } 532}=1.462271-3.587 * 10^{-4} \cdot(T-20), \text { or } \\
& n_{\text {Oil } 532}=1.469445-3.587 * 10^{-4} \cdot T \quad(T \text { in degrees } \mathrm{C})
\end{aligned}
$$

The index-of-refraction of fused silica (fused quartz) at $532 \mathrm{~nm}$ as a function of temperature was determined using Heraeaus data ${ }^{12}$ and the Sellmeier equation. ${ }^{13}$ The resulting relation with the Heraeus data is

$$
n_{Q r t z 532}=1.46071-9.975 * 10^{-6} \cdot T \quad(\mathrm{~T} \text { in degrees } \mathrm{C})
$$

where the change in index relative to wavelength was determined by a least squares curve fit of the Heraeus data verified against the listed index at $532 \mathrm{~nm}$ and the change in index relative to temperature was determined from the Heraeus data for the temperature coefficient. The resulting relation with the Sellmeier equation is

$$
n_{Q r t z 532}=1.4607063-1.28 * 10^{-5} \cdot T \quad(T \text { in degrees } \mathrm{C})
$$

where the change in index relative to wavelength was determined by applying of the Sellmeier equation for $532 \mathrm{~nm}$ and the change relative to temperature was established as $1.28 \times 10^{-5} /{ }^{\circ} \mathrm{C}$.

A third method using a least squares curve fit of data in the ESCO Products Handbook was evaluated but rejected because the resulting index-of-refraction of fused silica at $532 \mathrm{~nm}$ was sufficiently greater than that determined by the preceding two methods to warrant rejection.

The index-matching temperature was calculated by setting the above two equations equal to one another and solving for $\boldsymbol{T}$. The resulting matching temperature is

$\mathrm{T}_{\text {Matching }}=25.1516^{\circ} \mathrm{C}$. 


\section{PROPERTY VALUES}

In accordance with the analysis completed by Budwig and Weston ${ }^{10}$ the index-of-refraction, density, and viscosity of mineral oil at index-matching temperature are:

Index-of-refraction, $n: 1.458377( \pm 0.0003)$

Density, $\rho: 830.484228 \mathrm{~kg} / \mathrm{m}^{3}\left( \pm 0.24 \mathrm{~kg} / \mathrm{m}^{3}\right)$

Kinematic viscosity, $v: 1.32678510^{-5} \mathrm{~m}^{2} / \mathrm{s}\left( \pm 7.5 \cdot 10^{-8} \mathrm{~m}^{2} / \mathrm{s}\right)$.

\section{CAMERA-LASER MOVEMENT COORDINATION}

Because the line-of-sight of the cameras must pass through air, the soda-lime float glass windows, mineral oil in the test section, and the quartz model while the laser is orthogonal to the test section, an analysis of the movement ratio between the camera plane and light sheet plane was required. Based on the various indexes of refraction and viewing angle of the cameras at matching temperature, the movement ratio of the camera $\left.{ }_{(z \text { Camera }}\right)$ to the laser $\left._{(z \text { Laser }}\right)$ is

$\frac{z_{\text {Camera }}}{z_{\text {Laser }}}=0.567$

\section{MODEL COORDINATE SYSTEM AND ORIGIN}

The model origin is located at the vertex of the upper SFE interior gap wall at the interface between the inlet plenum and upper plenum (aluminum section) as shown in the following Figure 7.

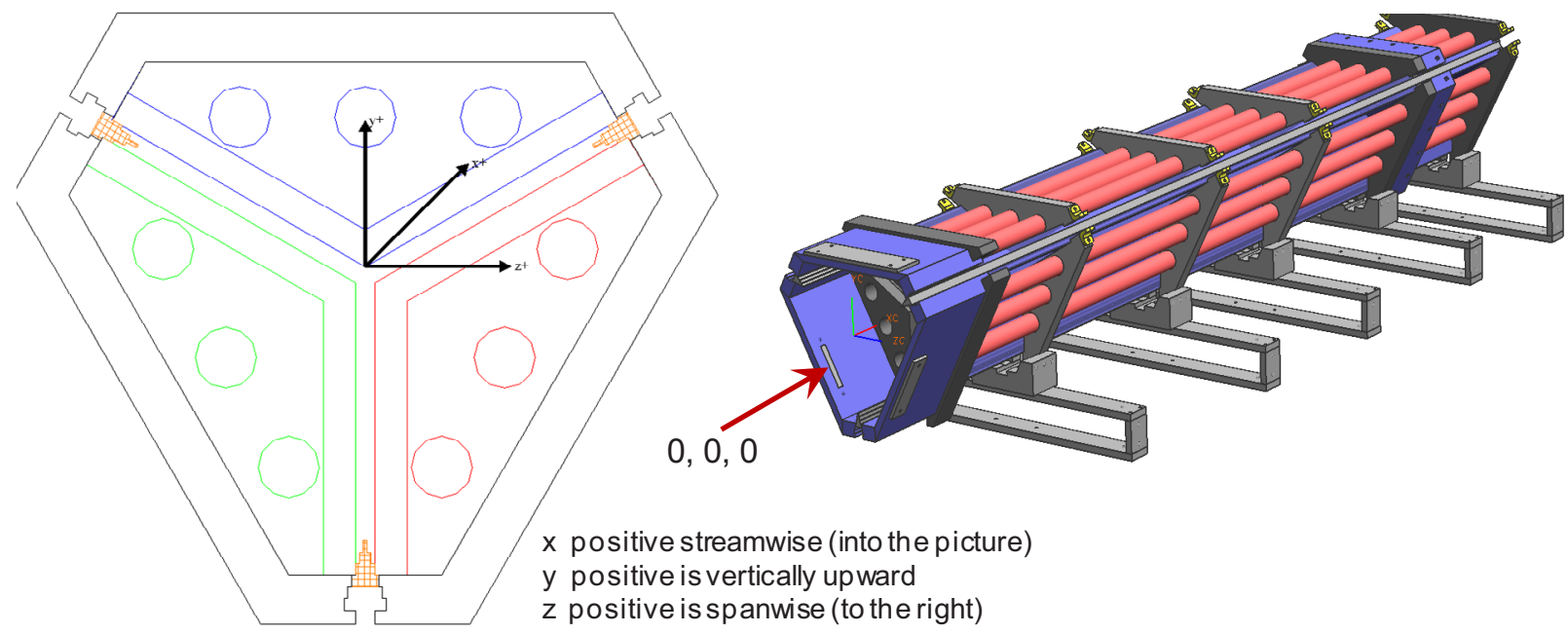

Figure 7. Model coordinate system and origin.

\section{MODEL AND LASER ALIGNMENT}

The traverse rails, traverse system vertical stage plates, camera rail, laser traverse rails, and test section centerline were aligned from a vertical reference line established parallel to the centerline of the test section with a ZEISS Model Th43 Theodolite and a Lufkin 6-ft Engineer's rule. A vertical reference line, established with the theodolite, parallel to the centerline of the test section was used to align the 
various components of the PIV system, model, and laser. The theodolite was also used to establish a horizontal reference line to level the traverse rails and laser rails.

\section{REFERENCE DATA SET}

A reference data set was collected on 9 August 2011. This data set consisted of stereo PIV images along the coolant channel centerlines of three coolant channels at the downstream location at the midlevel Reynolds number. A gap was not included in this reference data set. Each file consisted of 500 double images at a total flow rate into the model of about $580 \mathrm{~L} / \mathrm{min}$ (approximately $153 \mathrm{gpm}$ ). This volume flow rate corresponds to a Reynolds number based on the hydraulic diameter of the coolant channels of about 2,800 . This data set will be used to refine image collection parameters such as the: number of images required to minimize scatter in the mean velocities, camera lens size, lens f-stop setting, intensity ratio of background intensity to particle intensity, contrast, seeding density, light sheet thickness, time between images, sampling frequency, interrogation window size (for first and subsequent passes), post-processing operations, and post processing parameters and to help finalize some of the inputs to the ongoing uncertainty analysis.

Figures 8-13 display the results of the reference data set collection. Figures 8, 9, and 10 describe three very similar turbulent-like mean vector field velocity profiles, and Figures 11-13 confirm that these three velocity profiles are similar and representative of turbulent-like profiles. Interestingly, the two profiles in Figures 12 and 13 are symmetrical and nearly identical, while the profile in Figure 11 is not as symmetrical and appears to be skewed to the right, which is toward the top of the model as oriented in the test section. With the model oriented horizontally in the test section, this profile implies that buoyancy effects may be affecting the flow in this (bottom) channel. This situation will be thoroughly investigated by subsequent tests and data.

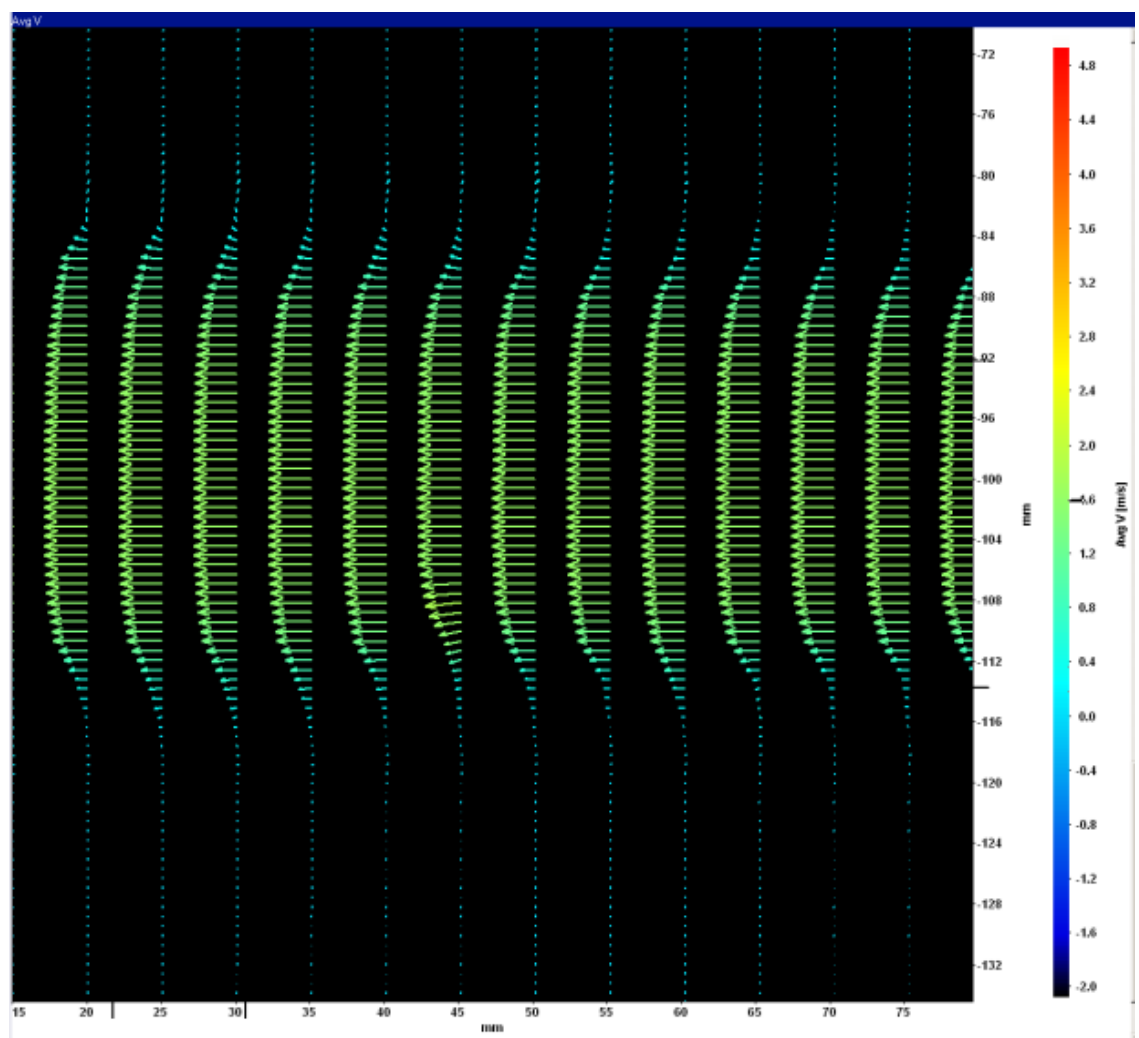

Figure 8. Bottom channel mean vector display. 


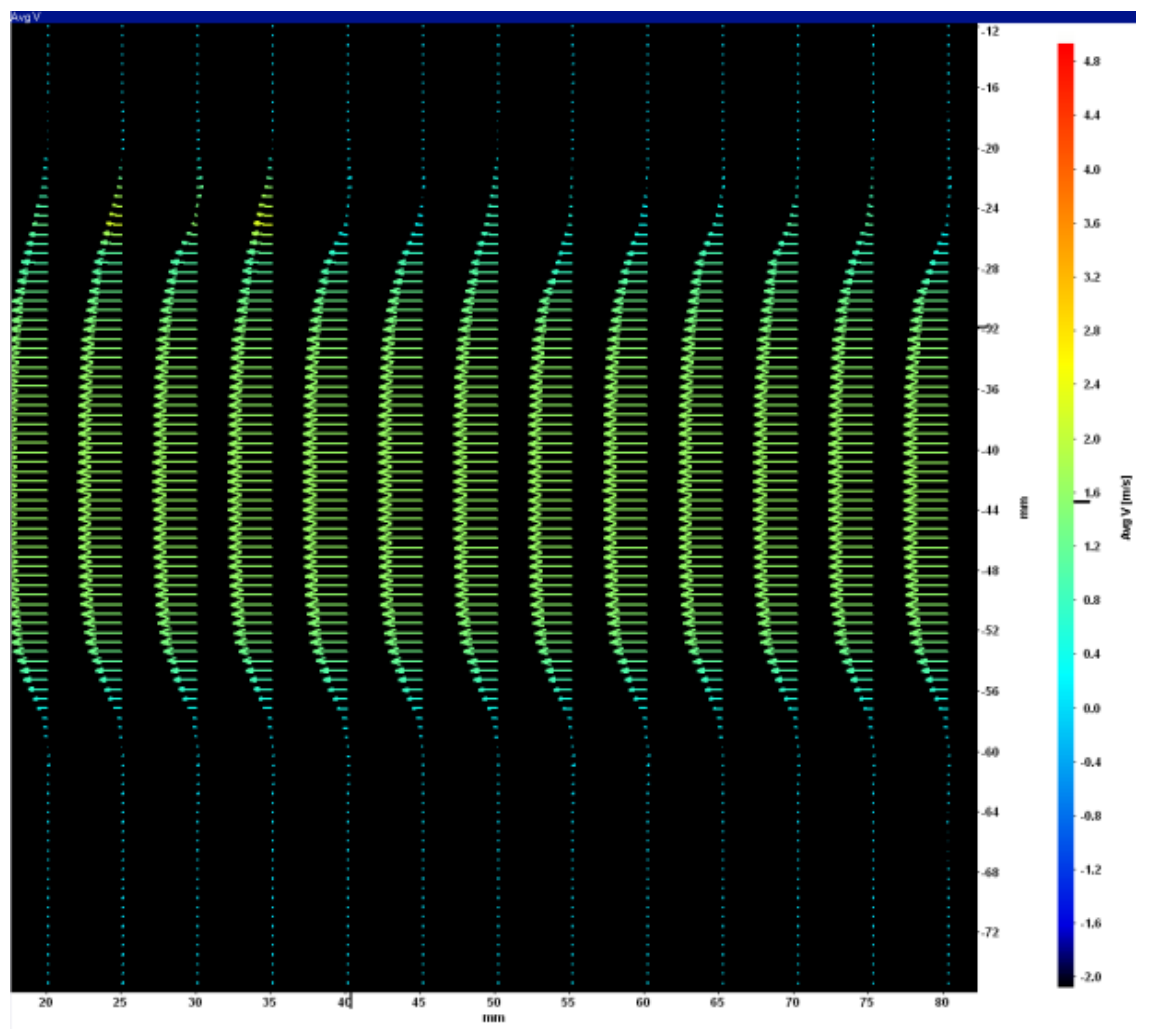

Figure 9. Middle channel mean vector display.

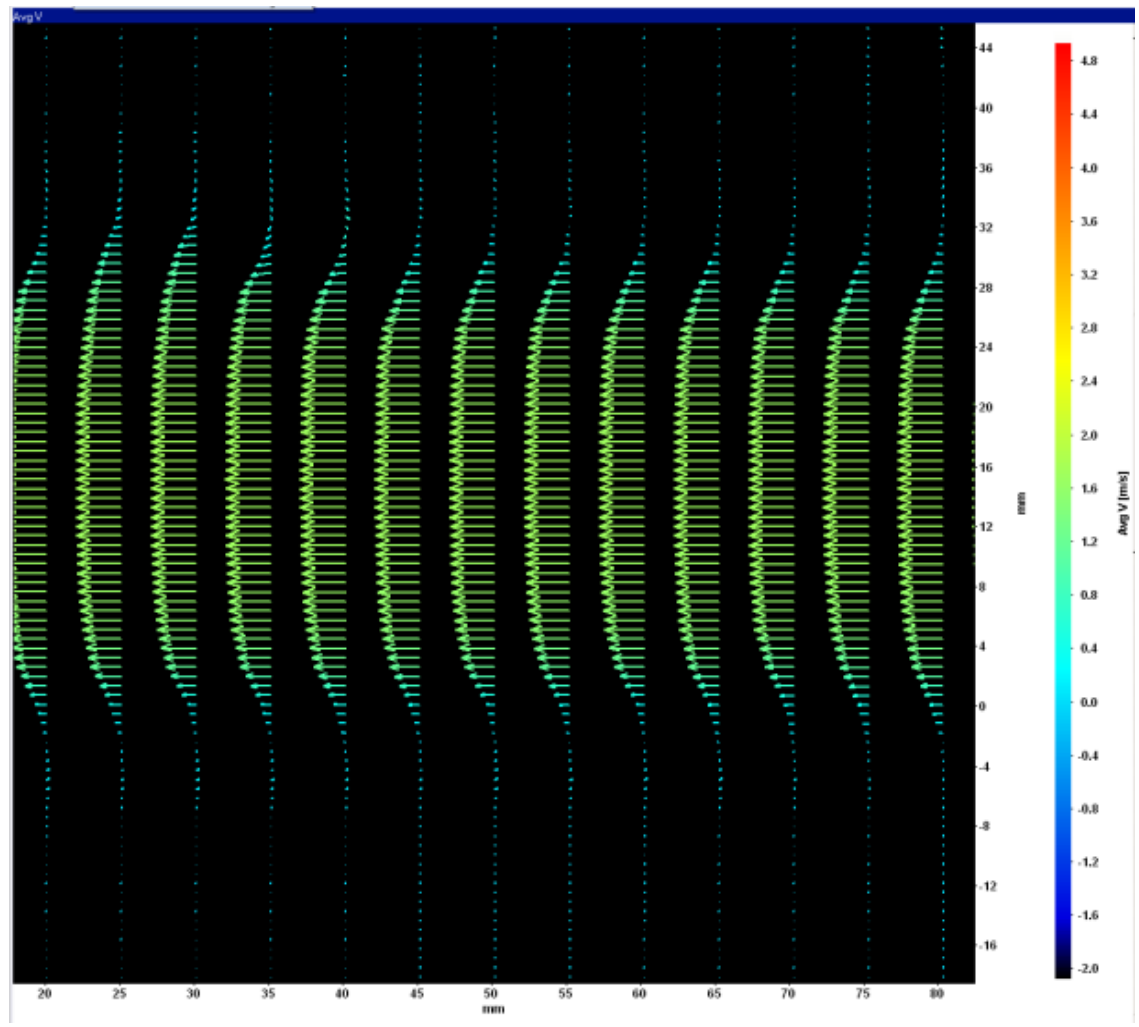

Figure 10. Upper channel mean vector display. 


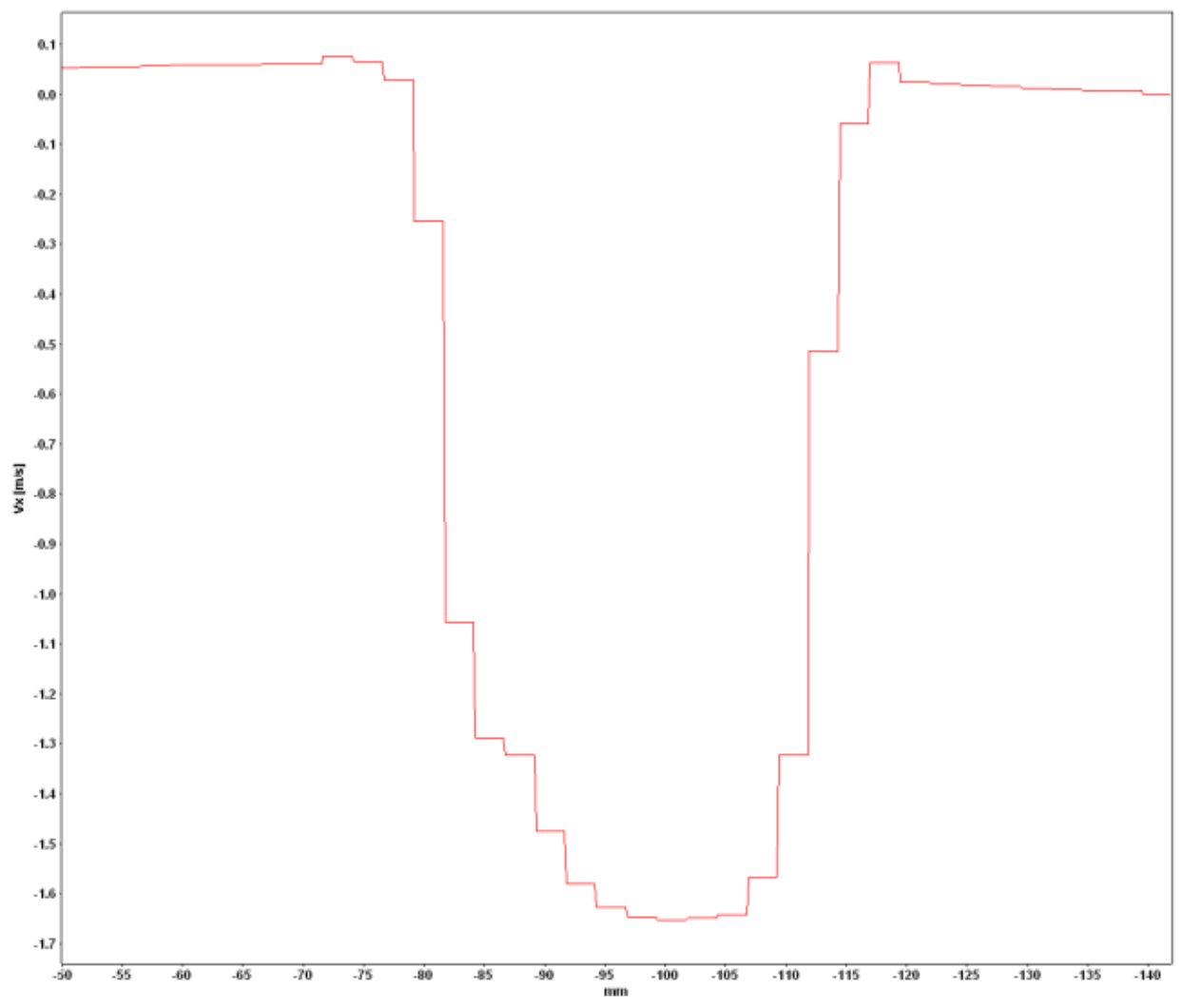

Figure 11. Bottom channel velocity profile.

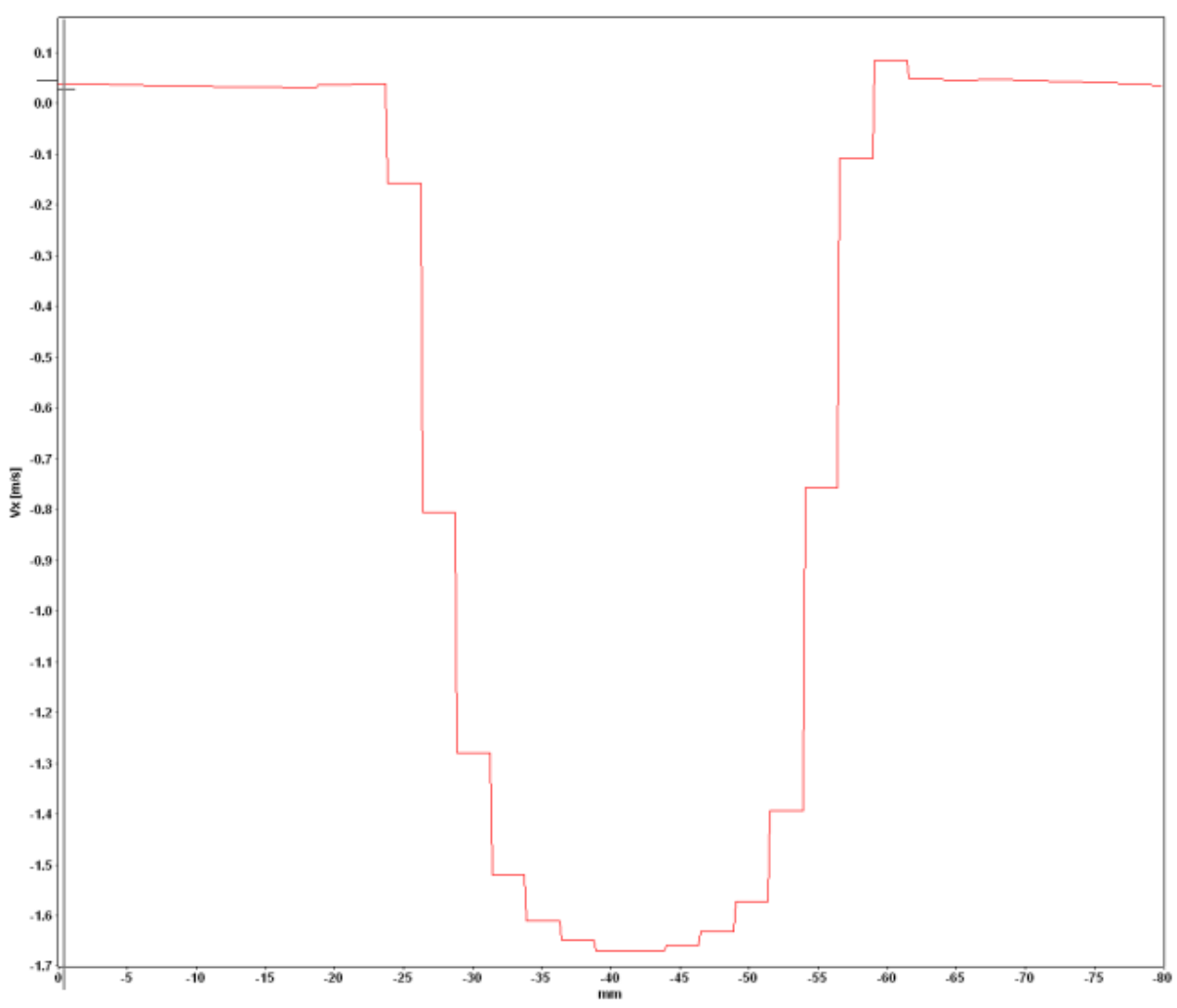

Figure 12. Middle channel velocity profile. 


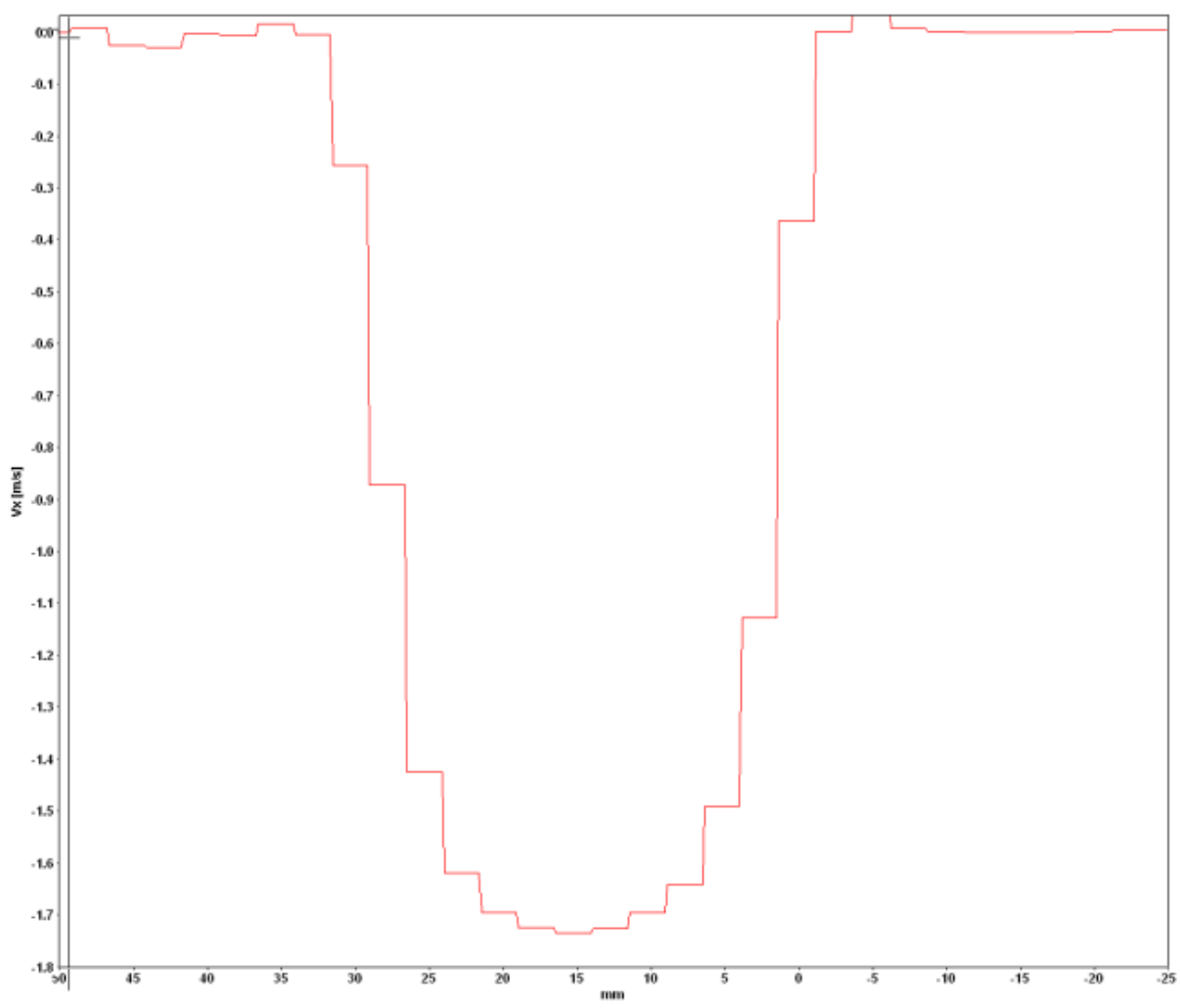

Figure 13. Upper channel velocity profile.

\section{SUMMARY AND ACTION PLAN}

The bypass flow model and stereo PIV systems are performing as designed and have produced a reference data set that will be highly valuable in refining the study parameters for collection of standard problem validation data sets. The reference data set confirms that the total hydraulic head analysis accurately predicts flow velocities and volume flow rates in the model, indicating that a Reynolds number based on coolant channel hydraulic diameter of about 2,800 is obtainable.

The results of the reference data set have been studied and refinements have been made to many of the study parameters. Present operations include collecting a second data set to confirm the benefit of the refinements that have been made and to conduct a detailed study of the number of double images that must be recorded to minimize the scatter in the mean velocities. The reference data set has also identified several modifications to the model that will be made when the model is removed to change the axial gap size. 


\section{REFERENCES}

1. Schultz, R. R., and M. H. Kim, 2009, Experimental and Analytic Study on the Core Bypass Flow in a Very High Temperature Reactor, First I-NERI Report, September.

2. Schultz ltr to H. Khalil and R. Versluis, "Project No: G-IN09VH0101-Methodology and Data for Validating the Computational Fluid Dynamics Calculations of the Core Flow Distribution and Bypass for the Very High Temperature Reactor," September 24, 2009.

3. McEligot, D. M., H. M. McIlroy, and R. C. Johnson, 2007, Estimated Uncertainties in the Idaho National Laboratory Matched-Index-of-Refraction Lower Plenum Experiment, INL/EXT-07-13539, Rev 0. November 2007.

4. International Towing Tank Conference (ITTC), 2008, "ITTC - Recommended Procedures and Guidelines Uncertainty Analysis Particle Imaging Velocimetry," ITTC paper 7.5-01-03-03, Rev 00.

5. McEligot et al., pp 21-32.

6. LaVision estimate. Also, PIV uncertainty is dependent on particle image diameter, interrogation window size, time delay between frames, turbulence intensity, image focus and image magnification (perhaps more). See Raffel, M., Willert, C. E. and Kompenhans, J., Particle Image velocimetry A practical Guide, 1998, Springer-Verlag Berlin Heidelberg New York, pp. 137 and 183.

7. Gas Turbine-Modular Helium Reactor (GT-MHR) Conceptual Design Description Report, 910720 Revision 1, July, 1996, pp. 4-5 to 4-10.

8. Sterbentz, James E., email, 07/09/2009,11:33 AM, Subj: Re: Fw: Standard Fuel Element Detail.

9. Richards, Matt, email, 07-13-2009, 3:25 PM, Subj: Re: Standard Fuel Element Detail with attachment Fuel-Element-Details.pdf

10. Budwig, R. and Westin, R., 2011, "Measurement of Oil Properties," Center for Echohydraulics Research, College of Engineering - Boise, University of Idaho, 1 June, p. 3.

11. McCreery, G.E., Index-Matching Temperature Calculations," MATHCAD Code, undated, Index Matching file.

12. Heraeus, "Quartz Glass for Optics Data and Properties," Heraeus Pamphlet POL-O/109 Ea, Ed. 1999.

13. Malitson, I. H., 1965, "Interspecimen Comparison of the Refractive Index of Fused Silica," J. of the Optical Society of America, Vol. 10, Oct. 1965, pp. 1205-1209. 